Archived version from NCDOCKS Institutional Repository http://libres.uncg.edu/ir/asu/

\title{
Appalachľan
}

B O O N E, N O R T H C A R O L I N A

\section{The Relationship Between Marriage and Family Therapists and Complementary and Alternative Medicine Approaches: A National Survey}

By: Karen L. Caldwell, Jon L. Winek, and

Dorothy S. Becvar

\begin{abstract}
Respondents to a mail survey of a random sample $(\mathrm{N}=424)$ of Clinical Members of the American Association for Marriage and Family Therapy provided information about their contexts of practice, use of complementary and alternative medicine (CAM), and relationships with CAM providers. Consistent with both national trends and the experience of psychologists as reported in a similar survey, the results of this survey suggest that marriage and family therapists have been affected significantly by and have a growing awareness of CAM practices. Limitations of the study and implications for the field are discussed.
\end{abstract}

Caldwell, K., Winek, J., \& Becvar, D. (2006). The relationship between marriage and family therapists and complementary and alternative medicine approaches: A national survey. Journal of Marital and Family Therapy, 32(1), 101-114. 


\title{
THE RELATIONSHIP BETWEEN MARRIAGE AND FAMILY THERAPISTS AND COMPLEMENTARY AND ALTERNATIVE MEDICINE APPROACHES: A NATIONAL SURVEY
}

\author{
Karen L. Caldwell and Jon L. Winek \\ Appalachian State University \\ Dorothy S. Becvar \\ Saint Louis University
}

\begin{abstract}
Respondents to a mail survey of a random sample $(\mathrm{N}=424)$ of Clinical Members of the American Association for Marriage and Family Therapy provided information about their contexts of practice, use of complementary and alternative medicine (CAM), and relationships with CAM providers. Consistent with both national trends and the experience of psychologists as reported in a similar survey, the results of this survey suggest that marriage and family therapists have been affected significantly by and have a growing awareness of CAM practices. Limitations of the study and implications for the field are discussed.
\end{abstract}

\section{INTRODUCTION}

It has been more than 10 years since marriage and family therapists (MFTs) were urged to overcome their ambivalence about the notion of illness and to "conceptualize and differentiate the varieties of illness/ distress from one another in order to clarify, strengthen, and broaden the scope of family therapy, theory, and clinical practice" (Wynne, Shields, \& Sirkin, 1992, p. 16). Since then, the overlap between family therapy and family medicine (Doherty \& Baird, 1983) has been acknowledged, and collaborative family health care has emerged as a distinct paradigm (Nichols \& Schwartz, 2004). Given an approach to health that is based on both a systemic perspective and an awareness of the fundamental connection between mind and body, one that is shared by family medicine practitioners, it is not surprising that many MFTs accepted the challenge to create models for collaborative practice (e.g., Cohen \& Milberg, 1992; Larivaara, Vaisanen, \& Kiuttu, 1994; Leff \& Walizer, 1992; McDaniel, Hepworth, \& Doherty, 1992; Miller, 1992; Rolland, 1994; Seaburn, Lorenz, Gunn, Gawinski, \& Mauksch, 1996; Stein, 1992; Wright, Watson, \& Bell, 1996). And over time, family therapists have become essential members of many medical contexts.

Today, both within and outside of medical settings, there also is increasing acknowledgment of the mind/body connection. An important manifestation of this shift is represented by expanding awareness and greater utilization of complementary alternative medicine (CAM). It thus seems appropriate to consider the extent to which MFTs have been affected by and/or are having an impact on this shift, including the

Karen L. Caldwell, PhD, and Jon L. Winek, PhD, Department of Human Development and Psychological Counseling, Reich College of Education, Appalachian State University; Dorothy S. Becvar, PhD, School of Social Service, Saint Louis University

Funding for this project provided by the University Research Council of the Cratis Williams Graduate School, Appalachian State University.

A special thank you to Karen Callahan, MS, for statistical consultation on this project.

Correspondence concerning this article should be addressed to Karen Caldwell, Associate Professor, Department of Human Development and Psychological Counseling, Appalachian State University, Boone, North Carolina, 28608; E-mail: caldwllk1@appstate.edu 
degree to which they once again may be expanding their scope of interest and practice. We begin this consideration with a review of the literature related to CAM practices and their use in general. We then describe a survey of a random sample of Clinical Members of The American Association for Marriage and Family Therapy (AAMFT) regarding their relationship with CAM practices. This is followed by a discussion of the results of a mail survey and subsequent data analysis. We conclude with some thoughts about implications and ramifications for the profession and the future.

\section{LITERATURE REVIEW}

The National Center for Complementary and Alternative Medicine (NCCAM; 2002), established in 1998 as a component of the National Institutes of Health, defines CAM as "a group of diverse medical and health care systems, practices, and products that are not presently considered to be part of conventional medicine" (p. 1). Complementary and Alternative Medicine therapies, which are subject to frequent change as various approaches are adopted into conventional health care, currently are classified into five categories: (1) Alternative Medical Systems, (e.g., Ayurveda, traditional Chinese medicine); (2) MindBody Interventions, (e.g., meditation, prayer); (3) Biologically Based Therapies (e.g., herbs, vitamins); (4) Manipulative and Body-Based methods (e.g., chiropractic, massage); and (5) Energy Therapies, either biofield therapies (e.g., qi gong, therapeutic touch), or bioelectromagnetic-based therapies (e.g., blue light treatment, electroacupuncture).

The results of several surveys indicated significant increases in the use of CAM in the United States during the decade of the nineties (cf, Astin, 1998; Eisenberg et al., 1993, 1998; Paramore, 1997; Rafferty, McGee, Miller, \& Reyes, 2001). More recently, a telephone survey (Barnes, Powell-Griner, McFann, \& Nahin, 2004) revealed that $36 \%$ of Americans had used some form of CAM therapy during the previous 12 months; when prayer related to one's health was included, this usage increased to $62 \%$. In this study, the most common reasons given for using CAM therapies included: (1) the experience of chronic or reoccurring pain, particularly back pain; (2) the belief that combining conventional medicine with CAM therapies helps; (3) the recommendation by a medical professional for CAM therapy; (4) the belief that conventional medicine could not help with a particular problem; and (5) the experience of conventional medicine as too costly. Indeed, for many reasons there seems to be little doubt that not only is CAM here to stay, but that more and more people will continue to avail themselves of one or more CAM services, particularly for chronic conditions, including anxiety and depression (Eisenberg et al., 1993, 1998).

Given that this increase in interest and use, particularly for problems, such as anxiety and depression, the perceptions of mental health professionals regarding CAM have become a subject for investigation. For example, a recent mail survey by Bassman and Uellendahl (2003), which sought to understand the use of CAM practices in the clinical work of psychologists, revealed some interesting trends. Among the findings was that "the percentage of respondents claiming expert or good knowledge in specific healing arts ranged from $10.0 \%$ for body work modalities to $59.8 \%$ for nutritional supplements" (p. 267). Only a few of the psychologists reported direct use of specific alternative healing practices. Further, they were more likely to recommend various modalities than to refer, with one-half the group indicating interest in learning more.

In the field of MFT, a few articles have provided information on the role of CAM from either a theoretical (Becvar, Cook, \& Pontius, 1998) or a practice perspective (Meyerstein, 2000). However, at this point, there is no other research whose focus was the prevalence of use of CAM by MFTs or the relationship between MFTs and CAM practitioners. Nevertheless, increased interest in this area, as well as the reality that MFTs may be very much involved, is indicated by the fact that the AAMFT website includes a section entitled, "Guidelines for Nontraditional Techniques." These guidelines were drawn from an article originally published more than a decade ago (Haug, 1994). Given the fact that a recent survey revealed that after marital/couple difficulties, depression and anxiety were the most common problems presented to MFTs (Northey, 2002), it behooves us to recognize that the future of MFT certainly may be influenced by practice modalities that today are considered alternative. Although there is considerable impetus for MFTs to use empirically supported treatments, it is also important for researchers to learn 
about and listen to the wisdom of good clinicians. We can easily lose sight of the fact that tomorrow's standard of care may include today's CAM practices.

Our research project, therefore, was designed to assess the perceptions of MFTs regarding CAM practices as well as the prevalence of their inclusion in clinical work. We conducted a mail survey of a national sample of Clinical Members of AAMFT to address the following research questions: (1) Are MFTs aware of serving clients who utilize CAM practices?; (2) how have MFTs incorporated CAM practices into their clinical work?; (3) if MFTs have incorporated CAM practices into their clinical work, with what types of clients and client problems have these practices been implemented?; and (4) how did MFTs learn to implement, refer to other practitioners, or integrate these practices into their clinical models?

\section{METHOD}

\section{Survey Procedures and Participants}

A sample of 1000 AAMFT Clinical Members was randomly selected from the more than 23,000 professionals who were active in the membership database in the spring of 2003. Surveys were sent to this random sample along with a self-addressed, stamped envelope for return of the instrument. After 2 weeks, a letter was sent to the entire sample encouraging all who had not returned a survey to please do so. After 3 weeks, a follow-up postcard was sent to people who had not yet responded.

The Institutional Review Board of Appalachian State University approved all research procedures and instrumentation. A cover letter was included with each mailed survey to explain the purposes of the study and solicit return of the questionnaires. Consent was implied with return of the completed survey. Questionnaires were numbered to allow follow-up correspondence to be sent to nonresponders. The list of questionnaire numbers with the sample names was kept in a locked file cabinet separate from the received questionnaires so that responses could remain anonymous. Returned questionnaires were kept locked in the offices of the principal investigator and were destroyed when the data analysis was completed. The participant contact list also was destroyed at that time. The data analysis was conducted using the Statistical Package for the Social Sciences version 11.5 for Windows (SPSS, 2002).

The final response rate was $44.3 \%$, or 424 of the 958 eligible therapists ( 7 surveys not deliverable and 35 members no longer practicing). This is a common response rate for busy professionals and compares favorably with Northey's (2005) $49.6 \%$ response rate for a mail survey of MFTs regarding their practice patterns, Bassman and Uellendahl's (2003) 20.2\% response rate for a mail survey of psychologists regarding their relationship with CAM practitioners, and Doherty and Simmons' (1996) 34.3\% response rate for a mail survey of MFTs regarding their general practice patterns.

\section{Survey Instrument}

The process of developing the survey instrument involved several steps. More than 2 dozen publications were reviewed to learn what previously has been done to survey attitudes about CAM in a variety of professions. Particularly useful in this regard were articles by Finnigan (1991) and DeKeyser, Cohen, and Wagner (2001). In addition, the authors, all of whom are AAMFT Clinical Members, considered various issues that seemed to be particularly relevant to MFTs, such as the relevance of CAM use to the conduct of psychotherapy and the importance of collaborative practice with both conventional medical personnel and CAM practitioners.

For the purposes of this study we proposed that CAM therapies are those therapies available to the public but not widely integrated into the conventional medical community. The survey instrument was divided into four sections: (1) knowledge of and attitudes toward complementary and alternative medicine; (2) recommendation of CAM and relationship with CAM providers; (3) general practice patterns; and (4) attitudes about complementary and alternative medicine. To encourage a high response rate, the survey instrument was designed to take only 20 minutes to complete.

In the section on knowledge of and attitudes toward CAM, we listed 26 practices by name (see Table 1). For each practice, respondents were asked to check a box indicating knowledge of the practice, whether they had used the practice, whether they had at least one client who had used the practice within the last 


\section{Table 1}

Frequency of Responses to Five Levels of Knowledge of Complementary and Alternative Medicine $(C A M)(\mathrm{N}=424)$

\begin{tabular}{|c|c|c|c|c|c|}
\hline Specific CAM Practice & $\begin{array}{l}\text { Know } \\
\text { about }\end{array}$ & $\begin{array}{l}\text { Have } \\
\text { used }\end{array}$ & $\begin{array}{l}\text { Clients } \\
\text { use }\end{array}$ & $\begin{array}{l}\text { Conduct/ } \\
\text { practice }\end{array}$ & $\begin{array}{l}\text { Teach/ } \\
\text { supervise }\end{array}$ \\
\hline Ayurveda & 129 & 29 & 30 & 1 & 0 \\
\hline Homeopathic & 303 & 131 & 166 & 4 & 1 \\
\hline Native American & 187 & 31 & 63 & 4 & 1 \\
\hline Traditional oriental medicine & 205 & 71 & 90 & 4 & 1 \\
\hline Naturopathy & 170 & 64 & 87 & 3 & 0 \\
\hline Curanderismo & 52 & 6 & 18 & 0 & 0 \\
\hline Acupuncture & 332 & 114 & 199 & 2 & 2 \\
\hline Chiropractic & 327 & 212 & 260 & 1 & 0 \\
\hline Massage & 321 & 237 & 260 & 4 & 2 \\
\hline Therapeutic touch & 255 & 106 & 96 & 23 & 3 \\
\hline Shiatsu & 172 & 71 & 52 & 0 & 0 \\
\hline Acupressure & 275 & 120 & 105 & 12 & 1 \\
\hline Guided imagery & 328 & 309 & 246 & 204 & 66 \\
\hline Hypnosis & 340 & 185 & 183 & 106 & 26 \\
\hline Biofeedback & 319 & 119 & 137 & 37 & 13 \\
\hline Meditation & 336 & 286 & 257 & 147 & 49 \\
\hline Prayer therapies & 251 & 171 & 178 & 94 & 37 \\
\hline Relaxation techniques & 332 & 332 & 289 & 231 & 84 \\
\hline Movement therapies & 242 & 107 & 92 & 22 & 11 \\
\hline Expressive arts & 242 & 132 & 126 & 57 & 24 \\
\hline Electromagnetic therapies & 188 & 32 & 38 & 5 & 1 \\
\hline Chelation therapy & 124 & 13 & 23 & 0 & 0 \\
\hline Metabolic therapy & 67 & 8 & 12 & 1 & 1 \\
\hline Diet/lifestyle changes & 320 & 299 & 281 & 140 & 42 \\
\hline Nutritional supplements & 295 & 248 & 236 & 36 & 10 \\
\hline Herbal medicine & 255 & 176 & 182 & 21 & 6 \\
\hline \multicolumn{6}{|c|}{ Others listed by more than one respondent: } \\
\hline EMDR $^{*}$ & 12 & 11 & 11 & 12 & 1 \\
\hline Reiki & 6 & 6 & 5 & 4 & 2 \\
\hline Thought field therapy & 4 & 3 & 3 & 3 & 1 \\
\hline Jin shin jyutzu & 2 & 2 & 1 & 0 & 0 \\
\hline Energy therapy & 3 & 3 & 1 & 0 & 0 \\
\hline Reflexology & 2 & 2 & 1 & 0 & 0 \\
\hline
\end{tabular}

year, whether they were qualified to conduct/practice that modality, and whether they were qualified to teach/supervise that modality.

In the section on the recommendation of CAM and relationship with CAM providers, respondents were asked about patterns of referrals made to and received from CAM providers. This section allowed for open-ended responses about the various referral relationships that MFTs may have with CAM providers.

The general practice patterns section of the instrument was modeled after the survey of practice patterns among MFTs conducted by Doherty and Simmons (1996). This section contained questions about 
Table 2

Marriage and Family Therapy (MFT) Practitioner Profile $(\mathrm{N}=424)^{*}$

Primary Professional Identification

MFT

Counselor

Social worker

Psychologist

Nurse

Clergy

Physician

Other

$\begin{aligned} 61.2 \% & (\mathrm{n}=256) \\ 10 \% & (\mathrm{n}=42) \\ 7.2 \% & (\mathrm{n}=30) \\ 7 \% & (\mathrm{n}=29) \\ 1.2 \% & (\mathrm{n}=5) \\ 5.3 \% & (\mathrm{n}=22) \\ .2 \% & (\mathrm{n}=1) \\ 7.9 \% & (\mathrm{n}=33)\end{aligned}$

Highest professional degree

PhD
MA
MS/MEd
MSW
DMin
EdD
MDiv
PsyD
Other

License held

Single license

MFT

$41.8 \%$

$3.4 \%$

$(\mathrm{n}=174)$

Social Work

Counselor

Psychology

$2.4 \%$

$(\mathrm{n}=14)$

RN

$1.9 \%$

$(\mathrm{n}=10)$

$<1 \%$

$(\mathrm{n}=8)$

$(\mathrm{n}=1)$

Dual license

MFT/Counselor

MFT/Social Work

$21.4 \%$

$(\mathrm{n}=89)$

MFT/Psychology

$11.5 \%$

$(\mathrm{n}=48)$

MFT/RN

$5 \%$

$(\mathrm{n}=21)$

Psychology/Counselor

$<1 \%$

$(\mathrm{n}=3)$

MFT/MD

$<1 \%$

$(\mathrm{n}=1)$

$<1 \%$

$(\mathrm{n}=1)$

No License**

$4.6 \%$

$(\mathrm{n}=19)$

Triple License

$6.5 \%$

$(\mathrm{n}=27)$

"Not all respondents completed each item.

${ }^{* *}$ Some states do not license MFTs so it is possible for Clinical Members of the American Association for Marriage and Family Therapy to practice in these states without a license.

professional identification, amount of practice, amount of experience, most common presenting problem, type of clients served, and basic demographic information.

The final section of the survey contained 22 attitudinal statements about CAM practices. These items were scored on a 5-point Likert scale from strongly agree (1) to strongly disagree (5). 
Table 3

Most Common Presenting Problems $(\mathrm{N}=410)$

\begin{tabular}{|c|c|c|c|c|}
\hline & Most common & Second most common & Third most common & Total \\
\hline Marital/couple difficulties & $37.6 \%$ & $15.1 \%$ & $19.0 \%$ & $71.7 \%$ \\
\hline Depression & $27.6 \%$ & $25.1 \%$ & $17.3 \%$ & $70.0 \%$ \\
\hline Anxiety & $7.6 \%$ & $21.0 \%$ & $19.0 \%$ & $47.6 \%$ \\
\hline Parent-adolescent conflict & $6.3 \%$ & $13.2 \%$ & $7.8 \%$ & $27.3 \%$ \\
\hline Child behavior problems & $6.3 \%$ & $6.8 \%$ & $4.1 \%$ & $17.3 \%$ \\
\hline Drug/alcohol abuse & $2.4 \%$ & $4.4 \%$ & $7.1 \%$ & $13.9 \%$ \\
\hline School problems & $2.7 \%$ & $2.9 \%$ & $5.1 \%$ & $10.7 \%$ \\
\hline Work difficulties & $0.5 \%$ & $2.0 \%$ & $5.6 \%$ & $8.0 \%$ \\
\hline Other & $2.7 \%$ & $1.7 \%$ & $3.4 \%$ & $7.8 \%$ \\
\hline Sexual abuse & $1.7 \%$ & $2.0 \%$ & $3.7 \%$ & $7.3 \%$ \\
\hline Other adult psychological problems & as $2.0 \%$ & $1.2 \%$ & $1.7 \%$ & $4.9 \%$ \\
\hline Chronic mental illness & $2.0 \%$ & $1.2 \%$ & $1.5 \%$ & $4.6 \%$ \\
\hline Child abuse & $0.2 \%$ & $1.7 \%$ & $1.5 \%$ & $3.4 \%$ \\
\hline Other child psychological problems & is $\quad 0.2 \%$ & $1.7 \%$ & $1.0 \%$ & $2.9 \%$ \\
\hline Domestic violence & $0.5 \%$ & $0.2 \%$ & $1.0 \%$ & $1.7 \%$ \\
\hline
\end{tabular}

\section{RESULTS}

\section{Practitioner Profile}

There were more female $(57 \%, n=239)$ than male $(43 \%, n=182)$ respondents, and the average age was 57 years, ranging from 31 to $81(S D=9.6)$. The respondents were experienced in MFT practice ( $M=19$ years posttraining, $S D=8.1$, mode $=20$, minimum $=2$, maximum $=41$ ) reporting an average number of clinical contact hours per week of $20.4(S D=10.7)$. Forty-six different states were represented.

The majority (60\%) of the respondents reported that their highest degree was at the master's level, and nearly $40 \%$ reported having completed a doctoral degree. One-third $(n=146)$ had a degree specifically in MFT, and one-quarter $(n=119)$ had a degree in psychology. The majority of the respondents $(61.2 \%, n=256)$ identified themselves primarily as MFTs, whereas the remainder identified themselves primarily as counselors, social workers, clergy, nurses, and other professionals (see Table 2). Most (95\%, $n=397$ ) of the respondents were licensed/certified as mental health practitioners, and a majority of the respondents $(80.3 \%, n=374)$ held a license or certification in MFT.

\section{Description of Clinical Settings and Clients Seen}

More than one-half the respondents $(65 \%)$ saw most of their clients in a private practice setting, and $11 \%$ saw most of their clients in a private, nonprofit setting. Most clinicians had provided direct services during the past year to clients of more than one ethnicity; $89 \%$ served European Americans, $71.3 \%$ served African Americans, and 64.6\% served Hispanics. Fewer clinicians reported seeing Asian Americans (37.4\%), American Indians (25.9\%), and other ethnic groups (7\%). Most clinicians had provided direct services to adolescents aged 11-17 and adults 18-64 years of age in the last year. Less than one-half (44\%) saw children 10 years of age and younger, and slightly more than one-half (56\%) saw adults aged 65 and older. The five most commonly cited presenting problems were marital/couple difficulties, depression, anxiety, parent-adolescent conflict, and child behavior problems (See Table 3). These presenting problems are the same as those reported from a national telephone survey focused on the practice patterns of MFTs (Northey, 2002). 


\section{MFT Knowledge of and Relationships with CAM Practices and Practitioners}

Knowledge of specific CAM practices. Seventy-one percent or more of the respondents indicated they know about the CAM practices of hypnosis, meditation, relaxation techniques, acupuncture, guided imagery, chiropractic, massage, diet/lifestyle changes, biofeedback, and homeopathic medicine. ${ }^{1}$ Twentyone additional practices were listed by a respondent one time. About one-half the respondents $(53.3 \%)$ indicated a little interest in knowing more about CAM, 30.4\% indicated a strong interest in knowing more, and $16.3 \%$ indicated no interest in knowing more.

Personal use and client use of CAM practices. Respondents indicated that they personally have tried a variety of CAM practices. The 10 most commonly used were relaxation techniques, guided imagery, diet/ lifestyle changes, meditation, nutritional supplements, massage, chiropractic, hypnosis, herbal medicine, and prayer therapies. This list of practices most commonly used by the clinician respondents was similar to that reported by clinicians as having been used by their clients. The exceptions to this were that client use included acupuncture in the top 10 practices, a practice not in the top 10 used by clinicians. Clinicians included prayer therapies in their top 10 practices.

Qualified to practice or teach. The percentages of respondents indicating that they were qualified to conduct/practice a specific treatment were understandably lower than the general knowledge of, personal use of, or awareness of clients' use of the practices. Greater than $20 \%$ of the respondents feel qualified to conduct or practice the following: relaxation techniques, guided imagery, meditation, diet/lifestyle changes, hypnosis, and prayer therapies. Even fewer respondents indicated that they are qualified to teach or supervise a specific practice. Relaxation techniques and guided imagery were the two practices most often endorsed in the category of qualified to teach/supervise.

Recommending CAM. Of the 411 respondents who answered the question, most ( $n=362,88.1 \%$ ) replied that they do recommend CAM practices to their clients. Most of these respondents $(n=313)$ answered a follow-up question in which a total of 50 different specific CAM practices were found to have been recommended to clients by this group. Seventy-four percent of all recommended CAM practices were (in order of descending frequency) the practices of relaxation, meditation, massage, diet/lifestyle changes, guided imagery, prayer, chiropractic, acupuncture, and hypnosis. The percent of clinicians recommending these practices ranged from $60.7 \%$ for relaxation to $19.2 \%$ for hypnosis.

Referring to CAM providers. Less than one-half of the respondents $(n=187,45.6 \%)$ indicated that they have a relationship with a CAM provider to whom they make referrals. When asked to indicate the practitioners to whom they refer, 51 different kinds of CAM practitioners were listed by the 174 clinicians who answered this question. Of those MFTs who responded to this question, 54.6\% $(n=95)$ made referrals to massage therapists, $39.7 \%(n=69)$ made referrals to chiropractors, $24.7 \%(n=43)$ made referrals to acupuncturists, and $11.5 \%(n=20)$ referred to homeopaths.

When asked to indicate the types of problems for which they refer to CAM providers, 142 respondents listed 78 different problems. These problems were designated into 11 categories to simplify the analysis: specific physical conditions $(n=83)$, pain $(n=58)$, stress $(n=57)$, anxiety $(n=38)$, depression $(n=31)$, other psychological/emotional difficulties $(n=27)$, trauma $(n=15)$, mind-body problems $(n=14)$, eating disorders and other diet problems $(n=14)$, addiction disorders $(\mathrm{n}=7)$, and spiritual problems $(n=3)$.

Receiving referrals from CAM providers. About one-third of the respondents $(n=126,31.7 \%)$ receive referrals from a CAM provider. When asked to indicate the practitioners from whom they receive referrals, 42 different types of CAM providers were listed by the 115 clinicians who answered this question. Marriage and family therapists receive referrals from massage therapists $(n=45)$, chiropractors $(n=41)$, acupuncturists $(n=14)$, MDs $(n=14)$, naturopaths $(n=8)$, pastors $(n=8)$, hypnotherapists $(n=8)$, homeopaths $(n$ $=7)$, movement therapists $(n=7)$, physical therapists $(n=6)$, and acupressure practitioners $(n=6)$.

When asked to indicate the types of problems for which CAM providers refer to them, respondents listed 54 different problems. These problem types were grouped into 12 general types to simplify the analysis. Relational problems $(n=55)$, depression $(n=44)$, anxiety $(n=37)$, other psychological difficulties $(n=37)$, stress $(n=24)$, and trauma $(n=16)$ were the most frequently listed.

Who is more likely to recommend CAM, refer to CAM providers, and receive referrals from CAM providers? A series of chi-square calculations and a $t$-test were calculated to examine possible associations 
Table 4

Results from VARIMAX Rotated Factor Analysis

\begin{tabular}{|c|c|c|c|}
\hline \multicolumn{2}{|c|}{ Item $^{\mathrm{a}}$} & \multirow{2}{*}{$\begin{array}{c}\text { Loading } \\
0.534\end{array}$} & \multirow{2}{*}{$\begin{array}{l}\text { Eigenvalue } \\
4.718\end{array}$} \\
\hline 7. & $\mathrm{CAM}^{\mathrm{b}}$ use should be supervised by physicians. & & \\
\hline 8. & CAM use can be dangerous. & 0.549 & \\
\hline 18. & CAM practices are generally just a financial con trick. & 0.675 & \\
\hline 19. & CAM should only be used as a last resort. & 0.573 & \\
\hline 9. & Clients can make adequate decisions about CAM. & 0.781 & 2.177 \\
\hline 10. & Explore clients' beliefs about CAM. & 0.785 & \\
\hline 17. & Health of body, mind and spirit are related. & 0.579 & \\
\hline 2. & Most clients are interested in CAM. & 0.625 & 1.329 \\
\hline 5. & Assumptions of CAM do not fit with psychotherapy. & 0.555 & \\
\hline & Build a collaborative practice with CAM practitioners. & 0.602 & \\
\hline & CAM outside the scope of practice of psychotherapists. & 0.576 & \\
\hline 21. & Serious concerns about CAM in practice of psychotherapy. & 0.509 & \\
\hline 14. & CAM should be regulated by peer review boards. & 0.704 & 1.211 \\
\hline & Therapists notify licensure boards about CAM. & 0.796 & \\
\hline & Not refer to CAM until I know about practice and practitioner. & 0.719 & 1.051 \\
\hline & Important to know about clients' CAM use. & 0.625 & \\
\hline
\end{tabular}

between variables describing the MFT clinicians. No difference in average age was found between those respondents who recommend CAM practices to clients and those who did not recommend CAM practices $(t=.057, p>.05)$. The highest degree of respondents was independent of whether they recommend CAM to their clients, whether they refer to a CAM provider, or whether they accept referrals from a CAM provider (all chi-square calculations were nonsignificant at the .05 level). Although there was independence between sex and recommending CAM practices and receiving referrals from CAM practitioners, there was a relationship between sex and whether the MFT practitioner referred to a CAM provider $(\Phi$ coefficient $=$ $.140, p=.005$ ). Women were slightly more likely than men to refer clients to CAM providers but were not more likely to receive referrals from CAM providers.

Primary professional identification was independent of whether respondents recommended CAM practices to their clients or referred them to a CAM practitioner. There was an association between primary professional identification and whether practitioners received referrals from CAM practitioners $(\Phi$ coefficient $=.182, p=.044)$. A higher percentage of psychologists received referrals than did those who identified themselves primarily as MFTs or other professionals. We are unsure of how to interpret this finding. Although psychologists were more likely to have a $\mathrm{PhD}$ than were those with other primary professional identifications, the highest educational degree of respondents was not associated with receiving referrals. It thus may be related to professional preference for a psychologist over members of other professions.

Finally, MFTs in private practice settings were more likely to recommend CAM practices to their clients $(\Phi$ coefficient $=-.102, p=.04)$, to refer to CAM practitioners $(\Phi$ coefficient $=-.241, p<.01)$, and receive referrals from CAM practitioners $(\Phi$ coefficient $=-.215, p<.01)$. Marriage and Family Therapists serving White clients were more likely to recommended CAM practices to their clients $(\Phi$ coefficient $=$ $-1.39, p=.005)$, but MFTs serving other race/ethnicities was independent of whether the MFTs referred to CAM practitioners or received referrals from CAM practitioners. 
What attitudes describe MFTs who recommend CAM, refer to CAM providers, and receive referrals from CAM providers? Respondents were asked to indicate their agreement or disagreement with 22 statements of attitudes about CAM commonly found in the literature. These items comprise the Attitudes Toward Complementary and Alternative Medicine Scale. The items that the respondents disagreed most strongly with were: (Item 1) Clients' use of CAM is irrelevant to the conduct of psychotherapy $(M=4.05$, $S D=1.02)$; (Item 5) The assumptions of CAM treatments do not fit well with my approach to psychotherapy $(M=4.03, S D=.92)$; (Item 18) CAM practices are generally just a financial con trick $(M=4.23, S D=.86)$; and (Item 19) CAM should only be used as a last resort when conventional treatments have nothing to offer $(M=4.07, S D=.83)$. The means overall suggest slight, rather than strong disagreement.

The statements that showed highest agreements were: (Item 3) I would not refer clients to a CAM health practitioner until I thoroughly knew about the practice and the practitioner $(M=1.54, S D=.93)$; (Item 4) It is important to know about clients' CAM use to better understand what they believe will support good health $(M=1.77, S D=.89)$; (Item 9) Well-informed clients can make adequate decisions about CAM treatments $(M=1.83, S D=.83)$; (Item 10) If clients believe a CAM treatment will help them, I would explore this treatment option with them $(M=1.73, S D=.81)$; and (Item 17) Health care providers should take into account that the health of body, mind and spirit are related $(M=1.37, S D=.80)$.

Items $2,3,4,9,10,11,12,16,17,20$, and 22 were reverse scored so that high scores would indicate positive attitudes towards CAM. The 22 items were then subjected to a VARIMAX rotated factor analysis to examine the underlying structure of these attitude statements. A five-factor solution was determined to account for $52 \%$ of the variance. Items loading .50 or above were taken to describe each factor. No item examined more than one factor at the same time (See Table 4). The first factor was labeled Caution, because agreement with these items reflected a need for caution when considering CAM practices. The second factor was labeled Client Responsibility, because the items referred to holistic approaches to client decision making. The third was labeled Fit, because the items concerned inclusion of CAM into psychotherapy practice. The fourth factor was labeled Regulation, because the items referred to the review and regulation of CAM practices. The fifth factor was labeled Knowing, because the items referred to the importance of knowing about CAM use or CAM health practitioners.

Factor scores were calculated by averaging the responses for items that loaded on a particular factor. Reliabilities of these factor scores were estimated using Cronbach's alpha and were acceptable given the small number of items in each factor (Factor $1=.62$, Factor $2=.74$, Factor $3=.67$, Factor $4=.53$, Factor $5=.46$, Total for all 16 items $=.7$ ). Average scores on the factor scores of the five factors were used in three follow-up discriminant analyses to classify respondents into groups based on whether respondents (1) recommend or do not recommend CAM, (2) refer or do not refer to a CAM provider, and (3) receive or do not receive referrals from a CAM provider.

Because most of the sample (88\%) did recommend CAM practices, the group sizes in the first discriminant analysis were too unequal to meet the assumption of equal population covariances. To address this issue, we selected a random sample of $14 \%$ of those who do recommend CAM practices $(n=52)$ for analysis with the 49 respondents who did not recommend CAM to clients. The five factor scores were entered stepwise into the equation and only one factor, Fit with Psychotherapy, produced a significant discriminant function (Wilks's lambda $\left.=.73, \chi^{2}=30.27, p<.0005\right)$. This factor assigned $28(61 \%)$ of 46 who did not recommend CAM and $42(82 \%)$ of 51 who did recommend CAM. The overall ability of this factor to discriminate between the groups was $72 \%$.

A discriminant analysis to classify those who do and those who do not refer to a CAM provider also was calculated using the five factor scores as predictor variables entered stepwise in the equation. Again, the only factor that produced a significant discriminant function was Fit with Psychotherapy (Wilks's lambda $\left.=.905, \chi^{2}=39.58, p<.0005\right)$. This factor correctly assigned $148(67.6 \%)$ of 219 who did not refer to a CAM provider and $104(57 \%)$ of 182 who did refer to a CAM provider. The overall ability of this factor to discriminate between the groups was $62.8 \%$.

A third discriminant analysis to classify those who did receive referrals from a CAM provider and those who did not receive referrals was calculated using the five factor scores as predictor variable (stepwise entry into equation). Fit with Psychotherapy was the only factor that produced a significant discriminant 
function (Wilks's lambda $\left.=.955, \chi^{2}=17.9, p<.0005\right)$. This factor correctly assigned $175(64.6 \%)$ of 271 who did not receive referrals from a CAM provider and 70 (55.6\%) of 126 who did receive referrals from a CAM provider. The overall ability of this factor to discriminate between the groups was $61.7 \%$.

The results of these analyses suggest that there is an association between therapists' beliefs in a fit between CAM and psychotherapy and recommending CAM, referring to a CAM provider, and receiving referrals from a CAM provider. We also found that expressing caution towards CAM, emphasizing client responsibility, belief in the need for regulation of CAM, and belief in the importance of knowing about CAM did not contribute to predicting those who would be involved with CAM when the attitudes toward fit with psychotherapy were taken into consideration.

\section{DISCUSSION}

As noted at the outset, this study was designed to assess the perceptions of MFTs regarding CAM practices as well as the prevalence of their inclusion in clinical work. Our first research question focused on learning whether MFTs are aware of serving clients who utilize CAM practices. Most of the respondents indicated knowledge of a variety of CAM practices as well as the fact that they do recommend CAM. Of these, not only were they aware of client use, but they themselves also were found to utilize a similar array of CAM services.

Our second question focused on understanding how MFTs have incorporated CAM practices into their clinical work. A relatively small number of respondents indicated that they were qualified to practice, supervise, or teach relative to a specific CAM modality. Such practices include relaxation techniques, guided imagery, meditation, diet/lifestyle changes, hypnosis, and prayer therapies. At the same time, a large percentage of this subgroup does recommend CAM practices to their clients. In addition, slightly less than one-half of the respondents acknowledged having a relationship with a CAM provider to whom they make referrals, and about one-third of the group received referrals from a CAM provider.

Question three was concerned with discerning the types of clients and client problems for which these practices had been implemented in instances where MFTs had incorporated CAM practices into their clinical work. Marriage and Family Therapists working with White clients were more likely than those working with other ethnicities to recommend CAM practices. At the same time, there was no difference in referrals to or from CAM practitioners relative to ethnicity. Respondents noted making referrals to CAM providers for stress, specific physical problems, pain, anxiety, depression, and a variety of other psychological and emotional difficulties.

Finally, question four focused on discovering how MFTs had learned to implement, refer to other practitioners, or integrate these practices into their clinical models. Given the importance attributed to having a thorough knowledge of a CAM practice before recommending or referring, it seems safe to conclude, pending further research, that learning occurred primarily through personal exploration. This would seem to be consistent with the findings regarding the perception of fit between CAM and psychotherapy among these respondents.

The findings of this study certainly are comparable to the results reported by Barnes et al. (2004) regarding the high percentage of use of CAM services in this country. In the professional arena, it appears that MFTs and psychologists (Bassman \& Uellendahl, 2003) also are experiencing a similar increase in awareness and utilization of CAM practices. To evaluate the generalizability of this latter inference, however, it is important to consider the degree to which respondents in this study were representative of Clinical Members of AAMFT as a whole.

In comparing the data from this survey with surveys conducted by Northey $(2002,2005)$ and Doherty and Simmons (1996), there are a number of similarities in the description of MFTs who responded to each. The majority of therapists were female and were very experienced in the practice of psychotherapy. The rate of MFTs holding a license or certification in MFT was $80 \%$ for both this study and the Northey (2002) study, but higher for the Northey (2005) study (88.8\%). The studies reported different rates of respondents who identify themselves primarily as MFTs (61\% for this study, 73\% for Northey's 2002 study, and $80.9 \%$ for Northey's 2005 study). The percentage of doctoral level MFTs (i.e., PhD, DMin, EdD, PsyD) 
was higher in this study (39.4\%) than that reported for the Northey (2002) sample (26\%). The presenting problems addressed by MFTs in the current study are identical to those reported by Northey (2002), and the average of 20 clinical contact hours per week is also consistent across three surveys (this survey; Doherty \& Simmons, 1996; and Northey, 2002). Although there are differences in the way the questions about primary practice setting were asked, the number of MFTs who work in private practice and those in organizational settings also seem to be similar across these three surveys.

Although we thus may claim that our sample seems to be representative of Clinical Members of AAMFT in general, we also acknowledge that given the broad definition of CAM used in this study, it is not surprising to learn that most respondents recommend CAM practices to their clients. For the purposes of this exploratory study, an inclusive definition was warranted. However, a number of practices included in the survey appear to have largely made the transition from alternative to mainstream practice, with $20 \%$ of the respondents reporting that they felt qualified to conduct or practice the use of relaxation techniques, guided imagery, meditation, diet/lifestyle changes, hypnosis, and/or prayer therapies.

\section{Clinical Implications}

The distinctions between what is mainstream and what is alternative are likely to continue to shift over time as patterns of practice continue to evolve. For example, family therapy was considered alternative at one time. Although many of the modalities in the category of CAM are far older and much better established than current Western medical practices, some were founded less than a decade ago. However, as the trend towards a greater understanding of the mind-body connection continues, practices that are based on this interconnection are likely to become even more widely accepted by MFTs.

At the same time, the shift in the awareness and utilization of CAM practices by MFTs suggested by this study indicates the potential for a variety of challenges in the legal and ethical domains. Those practices considered to meet standards of care are determined according to the standards commonly accepted by the profession. If therapists move beyond this realm in any way they may encounter problems. For example, counselors have been advised as follows:

If counselors employ unusual therapy procedures, they put themselves at risk. They bear the burden of demonstrating a rationale for their techniques. If it can be shown that their procedures are beyond the usual methods employed by most professionals, they are vulnerable to a malpractice action. If it is unlikely that an expert can be found to testify to the acceptability of a certain treatment approach, it would be prudent not to employ this approach. (Corey, Corey, \& Callanan, 1998, p. 142)

Consistent with the above, MFTs have been advised to "be aware of new developments, learn about them in detail, evaluate them carefully, and implement them in practice only with suitable training and supervision" (Denton \& Walsh, 2001, p. 84).

White (2000) considered the ethical and legal issues raised by incorporating nontraditional practices into psychotherapy in the field of psychology. She notes that the referral process is crucial given ethics code requirements for therapists to make referrals for adjunctive care responsibly and according to the needs of the patient. This may be challenging inasmuch as no states have clear policies regarding the use of CAM in mental health practices, although many states do have laws regulating who can touch clients. Additional issues of concern include dual licensure, which raises the specter of dual relationships, the lack of regulation of many CAM practices and practitioners, and the need for much greater empirical validation for specific modalities. It also is important to be aware of the differences between recommending CAM and recommending that a person perform a specific behavior related to CAM.

\section{Limitations and Future Directions for Research}

Finally, although this study, the first of its kind on this topic, provides important information about MFTs relative to their perceptions and use of CAM approaches, the results must be interpreted with several considerations and limitations in mind. Although the response rate was marginally acceptable for this study, this response rate is typical for mail surveys of busy professionals (Northey, 2005). Because the respondents 
in this study were similar to those in the Northey (2002) sample, which used a telephone survey methodology that yielded a response rate of $80 \%$, we believe the findings are not seriously compromised by the response rate.

However, one of the limitations of the study is the lack of information about those who did not participate in the study. Another limitation is that the sample is drawn from AAMFT Clinical Members, who are estimated to comprise only approximately $40 \%$ of the MFTs practicing in the United States (Northey, 2002; West et al., 2001). We therefore recommend additional studies of national samples, including samples of MFTs who are not members of AAMFT.

Although efficacy studies of some CAM approaches have been conducted and are currently underway, much more research is needed before firm conclusions can be made about which treatments may be most effective for which clients. Further research is also needed on collaborations between MFTs and CAM practitioners to identify types of referral situations, contextual, and relational factors that contribute to the enhancement of individual and family treatment. Because CAM practices can include such a broad range of treatments, researchers are encouraged to define clearly the practices included in their definition of CAM.

\section{CONCLUSION}

Consistent with a growing acknowledgement of the mind-body connection as well as various other related factors (Barnes et al., 2004), the awareness and utilization of CAM practices by both the general public and mental health professionals has been steadily increasing over the last 2 decades. Moreover, "due to high market demand, at least $67 \%$ of health insurers and HMOs, such as Blue Cross, Kaiser Permanente, Mutual of Omaha, Prudential, California Pacific, Catholic HealthCare West, HealthNet, and Oxford Health Plans, cover CAM therapies" (Complementary and Alternative Medicine Facts, 2004). It appears that CAM is having a similar significant impact on the field of MFT.

Given the results of this study, it is apparent that many MFTs and their clients are making recourse to various CAM approaches. It therefore behooves us as a field to continue our involvement in this realm in as responsible a manner as possible. For example, MFTs certainly might benefit from increased discussions and opportunities related to new, alternative, and/or experimental modalities. Indeed, without such a mind set, we might never have evolved as a field and a professional discipline. Further, if CAM practices are being used by MFTs, either in practice or through referrals, the field must respond with appropriate models for ethical decision making, educational programs, continuing professional development, and research studies focused on this area. Marriage and Family Therapists also may need to become advocates for further validation and regulation of CAM services in general. Just as MFTs responded to the call for practice models combining family therapy and family medicine, the time may have come for a similar response to CAM.

\section{REFERENCES}

Astin, J. N. (1998). Why patients use alternative medicine: Results of a national study. Journal of the American Medical Association, 279, 1548-1553.

Barnes, P. M., Powell-Griner, E., McFann, K., \& Nahin, R. L. (2004). Complementary and alternative medicine use among adults: United States, 2002. Hyattsville, MD: Advance Data from Vital and Health Statistics, no. 343, National Center for Health Statistics.

Bassman, L. E., \& Uellendahl, G. (2003). Complementary/alternative medicine: Ethical, professional, and practical challenges for psychologists. Professional Psychology: Research and Practice, 34, 264-270.

Becvar, D. S., Cook, C. L., \& Pontius, S. (1998). Complementary alternative medicine: Implications for family therapy. Contemporary Family Therapy, 20(4), 435-456.

Cohen, W., \& Milberg, L. (1992). The behavioral pediatrics consultation: Teaching residents to think systemically in managing behavioral pediatrics problems. Family Systems Medicine, 10, 169-179.

Complementary and Alternative Medicine Facts. (2004). Retrieved July 10, 2004, from http://www.medaus.com/p/ Functional-Medicine-Complementary-and-Alternative-Medicine-Facts

$142,181 . h t m l$ 
Corey, G., Corey, M., \& Callanan, P. (1998). Issues and ethics in the helping professions (5th ed.). Pacific Grove, CA: Brooks/ Cole.

DeKeyser, F. G., Cohen, B. B., \& Wagner, N. (2001). Knowledge levels and attitudes of staff nurses in Israel toward complementary and alternative medicine. Journal of Advances Nursing, 36, 41-48.

Denton, W. H., \& Walsh, S. R. (2001). Competence and integrity: Ethical challenges for today and the future. In R. H. Woody \& J. D. Woody (Eds.), Ethics in marriage and family therapy (pp. 83-101). Washington, DC: AAMFT.

Doherty, W. J., \& Baird, M. A. (1983). Family therapy and family medicine: Toward the primary care of families. New York: Guilford Press.

Doherty, W., \& Simmons, D. (1996). Clinical practice patterns of marriage and family therapists: A national survey of therapists and their clients. Journal of Marital and Family Therapy, 22, 9-25.

Eisenberg, D., Davis, R., Ettner, S., Appel, S., Wilkey, S., Van Rompay, M., \& Kessler, R. (1998). Trends in alternative medicine use in the United States, 1990-1997: Results of a follow-up national survey. Journal of the American Medical Association, 280, 1569-1575.

Eisenberg, D. M., Kessler, R. C., Foster, C., Norlock, F. E., Calkins, D. R., \& Delbanco, T. L. (1993). Unconventional medicine in the United States: Prevalence, costs, and patterns of use. New England Journal of Medicine, 328, 246-252.

Finnigan, M. D. (1991). Complementary medicine: Attitudes and expectations, a scale for evaluation. Complementary Medical Research, 5(2), 79-82.

Haug, I. (February, 1994). Guidelines for nontraditional techniques. Retrieved July 15, 2004, from http://www.aamft.org/ MEMBERS/ RESOURCES/LRMPLAN/ETHICS/ETH_NONTRADTECHNNIQUES.HTM. Original source: Notes from the ethics committee, Family Therapy News, 25(1), 27.

Larivaara, P., Vaisanen, E., \& Kiuttu, J. (1994). Family systems medicine: A new field of medicine. Nordic Journal of Psychiatry, 48, 329-332.

Leff, J. P., \& Walizer, E. (1992). The uncommon wisdom of parents in the moment. Family Systems Medicine, 10, $147-168$.

McDaniel, S., Hepworth, J., \& Doherty, W. (1992). Medical family therapy: A biopsychosocial approach to families with health problems. New York: Basic Books.

Meyerstein, I. (2000). Family therapy and alternative medicine: Acupuncture as a case in point. Contemporary Family Therapy, 22, 3-18.

Miller, W. (1992). Why family medicine? The sound of bells. Family Systems Medicine, 10, 347-357.

National Center for Complementary and Alternative Medicine. (2002). What is complementary and alternative medicine? Retrieved May 15, 2002, from http://nccam.nih.gov/health/whatiscam

Nichols, M. P., \& Schwartz, R. (2004). Family therapy: Concepts and methods (6th ed.). Boston: Allyn \& Bacon.

Northey, W. F. (2002). Characteristics and clinical practices of marriage and family therapists: A national survey. Journal of Marital and Family Therapy, 28, 487-494.

Northey, W. F. (2005). Studying marriage and family therapists in the 21st century: Methodological and technical issues. Journal of Marital and Family Therapy, 31, 99-105.

Paramore, L. C. (1997). Use of alternative therapies: Estimates from the 1994 Robert Wood Johnson Foundation National Access to Care survey. Journal of Pain and Symptom Management, 13, 83-89.

Rafferty, A. P., McGee, H. B., Miller, C. E., \& Reyes, M. (2001). Prevalence of complementary and alternative medicine use: State-specific estimates from the 2001 behavioral risk factor surveillance system. American Journal of Public Health, 92, 1598-1600.

Rolland, J. (1994). Helping families with chronic and life-threatening disorders. New York: Basic Books.

Seaburn, D. B., Lorenz, A. D., Gunn, W. B., Gawinski, B. A., \& Mauksch, L. B. (1996). Models of collaboration: A guide for mental health professionals working with health care practitioners. New York: Basic Books.

Statistical Package for the Social Sciences (2002) (Version 11.5 for Windows Operating Systems) [Computer software]. Chicago, IL: SPSS.

Stein, H. (1992). "The eye of the outsider": Behavioral science, family medicine, and other human systems. Family Systems Medicine, 10, 2293-2304.

West, J., Kohout, J., Pion, G. M., Wicherski, M. M., Vandivort-Warren, R. E., Palmiter, M. L., et al. (2001). Mental health practitioners and trainees. In M. J. Henderson \& R. W. Maderscheid (Eds.), Mental Health, United States, 2000 (pp. 279-315). Washington, DC: Center for Mental Health Services. DHHS Pub No. (SMA) 01-3537. Washington, DC: Supt. of Docs., U.S. Govt. Print Office.

White, K. P. (2000). Psychology and complementary and alternative medicine. Professional Psychology: Research and Practice, 31, 671-681.

Wright, L. M., Watson, W. L., \& Bell, J. M. (1996). Beliefs: The heart of healing in families and illness. New York: Basic Books.

Wynne, L. C., Shields, C., \& Sirkin, M. (1992). Illness, family theory, and family therapy: I. Conceptual issues. Family Process, 31, 3-18. 


\section{NOTE}

${ }^{1}$ Homeopathic medicine is an alternative medical system premised on a belief that small, highly diluted quantities of medicinal substances can cure symptoms. If the same substances were given at higher or more concentrated doses, they would actually cause the same symptoms they are designed to treat (NCCAM, 2002). 